\title{
Dolutegravir plus lamivudine versus efavirenz plus tenofovir disoproxil fumarate and lamivudine in antiretroviral-naive adults with HIV-1 infection
}

Lisi Deng ${ }^{1 \dagger}$, Chunna $\mathrm{Li}^{1 \dagger}$, Ping Chen ${ }^{1+}$, Xiaoqing Luo ${ }^{1}$, Xinchun Zheng ${ }^{1}$, Lanlan Zhou ${ }^{2}$, Yi Zhou $^{2}$, Jinyu Xia ${ }^{1}$ and Zhongsi Hong ${ }^{1 *}$

\begin{abstract}
Background: Concerns regarding potential toxicity and drug-drug interactions during long-term treatment with three-drug active antiretroviral therapy (ART) regimens have been attracting increasing attention. We aimed to evaluate the efficacy and safety of dolutegravir (DTG) plus lamivudine (3TC) in ART-naive adults in China.

Methods: This prospective observational cohort study enrolled HIV-naive inpatients treated with DTG + 3TC (2DR arm) or efavirenz (EFV) plus tenofovir disoproxil fumarate (TDF) and 3TC (3DR arm). There were no limits on baseline viral load. Inflammatory biomarkers were also investigated in the 2DR arm.

Results: Between September 2019 and January 2020, 27 patients treated with DTG + 3TC and 28 patients treated with EFV + TDF + 3TC were enrolled in the study. At week 12, the proportion of patients with viral loads $<50$ copies/ $\mathrm{mL}$ in the 2DR arm was $81.5 \%(22 / 27)$ compared with 53.6\% (15/28) in the 3DR arm ( $p<0.01)$. At week 24, the proportion of patients with viral loads $<50$ copies/mL in the 2DR arm was $100 \%(26 / 26)$ compared with $83.3 \%(20 / 24)$ in the $3 D R$ arm $(p<0.05)$. Mean changes in CD4 cell counts from baseline at week 12 were 125.46 cells $/ \mu \mathrm{L}$ in the $2 \mathrm{DR}$ arm and 41.20 cells/ $/ \mathrm{L}$ in the 3DR arm $(p<0.05)$. Mean changes in CD4 cell counts from baseline at week 24 were 209.68 cells $/ \mu \mathrm{L}$ in the $2 \mathrm{DR}$ arm and 73.28 cells/ $\mu \mathrm{L}$ in the 3DR arm $(p<0.05)$.
\end{abstract}

Conclusions: DTG + 3TC achieved virologic suppression more rapidly than EFV + TDF + 3TC after 12 and 24 weeks.

DTG + 3TC could represent an optimal regimen for advanced patients.

Clinical Trial Registration ChiCTR1900027640 (22/November/2019).

Keywords: Dolutegravir, Lamivudine, Two-drug regimen, Naive, HIV

*Correspondence: hongzhs@mail.sysu.edu.cn

${ }^{\dagger}$ Lisi Deng, Chunna Li and Ping Chen contributed equally to this work ${ }^{1}$ Department of Infectious Diseases, the Fifth Affiliated Hospital, Sun YatSen University, 52 East Meihua Road, Zhuhai 519000, Guangdong, China Full list of author information is available at the end of the article

\section{Introduction}

There has been a sustained decrease in the mortality and morbidity of patients with human immunodeficiency virus type 1 (HIV-1) infection since the introduction of highly active antiretroviral therapy (HAART) [1, 2]. However, with long-term use of HAART, problems can arise including adverse events (AEs) caused by antiretroviral drugs [3] and drug-drug interactions (DDIs) between HAART and other therapies for non-acquired 
immunodeficiency syndrome (AIDS)-related complications and anti-HIV-1 treatments [4]. Concerns related to the safety profiles of these medicines administered throughout the life course have attracted increasing attention. Specifically, patients with low CD4+cell counts or high viral loads at baseline (prior to HAART) occur commonly in China. An optimized regimen that is well suited to such patients with advanced disease is needed.

Two-drug regimens (2DRs) have been investigated as a means to improve the quality of life of patients with HIV-1 by reducing adverse drug reactions, saving costs, and improving HAART compliance [5-7]. Dolutegravir (DTG), a second-generation integrase strand transfer inhibitor (INSTI), is attractive as a component of 2DRs because of its high antiviral potency and resistance barriers [8-10]. Lamivudine (3TC) is also an effective component of 2DRs with a well-documented safety profile and a high barrier to resistance [11].

In the GEMINI trials, the antiviral activity of DTG + 3TC was similar to that of DTG + TDF/emtricitabine (FTC) in ART-naive individuals with baseline viral loads below 500,000 copies/mL; furthermore, no resistance was reported for up to 96 weeks [11]. Antiviral regimens containing INSTIs were effective in preventing long-term mitochondrial, bone, and renal toxicity [14]. Thus, DTG + 3TC might represent a viable 2DR for the treatment of HIV-1 infection in ART-naive individuals.

Currently, international guidelines recommend DTG + 3TC as the first-line regimen for ART-naive individuals with HIV-1 infection and viral loads $<500,000$ copies $/ \mathrm{mL}$. However, this regimen has not been evaluated in individuals with no limitations on viral loads and especially in individuals with baseline viral loads $>500,000$ copies $/ \mathrm{mL}$. In addition, there is limited experience with DTG + 3TC in China.

Several potential mechanisms to explain the relationship between inflammation and HIV-1 replication have been proposed [15-17]. One postulated mechanism for abnormal levels of inflammation and immune activation despite HAART is ongoing HIV-1 replication and/ or expression of HIV-1 gene products [16]. Additionally, levels of inflammatory markers including interleukin (IL)-6, D-dimer, soluble tumor necrosis factor receptor-1, high-sensitivity $C$ reactive protein (but not levels of T-cell activation, senescence, or exhaustion) are independently predictive of mortality in individuals with treated HIV-1 infection with a history of AIDS [18].

In this prospective cohort study, we aimed to evaluate the efficacy and safety of DTG + 3TC compared with a first line 3DR (EFV + TDF + 3TC) for treatment of HIV-1 infection in ART-naive adults in China with no limitations on baseline viral load.

\section{Methods}

This ongoing observational single-center prospective observational cohort study enrolled ART-naive individuals with HIV-1 infection referred to our hospital from September 2019 to January 2020. Data were collected from September 2019 to July 2021. No CD4 count restrictions nor limitations on baseline viral loads were imposed.

Exclusion criteria included pre-existing major viral resistance mutations to nucleoside reverse transcriptase inhibitors, non-nucleoside reverse transcriptase inhibitors, or protease inhibitors; active hepatitis B virus infection; anticipated hepatitis $\mathrm{C}$ treatment during the study period; unstable or severe hepatic impairment; alcohol or drug abuse; pre-existing mental disorders; and pregnancy.

The study was approved by the Research Ethics Committee of the Fifth Affiliated Hospital of Sun Yat-sen University (No. ZDWY [2019], Lunzi No. K16-1). Written informed consent was obtained from each participant prior to the initiation of study procedures. All study procedures were performed in accordance with relevant local guidelines and regulations. The study was registered in the Chinese Clinical Trial Registry: ChiCTR1900027640 (22/November/2019).

\section{Procedures}

HAART regimens were selected according to Chinese guidelines and patient requirements. For all patients, HAART regimens were selected on clinical grounds either because of concomitant diseases, the results of laboratory tests, financial reasons, AEs, or risk of DDIs.

Study visits were scheduled at baseline and weeks 2,4 , $8,12,24,36$, and 48 following HAART initiation. Renal function, liver enzymes, lipid profiles, blood counts, and bone mineral density were assessed at all study visits. Plasma HIV-1 RNA viral load was tested at weeks 12, 24, and 48 (Roche Diagnostics Limited, Shanghai, China). CD4 cell counts were determined at weeks $4,12,24$, and 48. Levels of inflammatory biomarkers in individuals in the 2DR arm were assessed at baseline and at weeks 2, 4, and 12 .

Safety, including AEs and serious AEs (SAEs), was assessed at each study visit. Events were graded according to the Division of AIDS Table for Grading the Severity of Adult and Pediatric Adverse Events, version 2.0 [19]. All SAEs and AEs of special interest were investigated until resolution, stabilization, loss of the patient to follow-up, or the event was otherwise explained.

\section{Outcomes}

The primary efficacy endpoint was the proportion of participants with virologic success, defined as HIV-1 
RNA viral load $<50$ copies $/ \mathrm{mL}$. The secondary endpoints included evaluating the efficacy, safety, and tolerability of HAART regimens, assessing changes from baseline in CD4 + cell counts, and assessing changes from baseline in the CD4+/CD8 + cell ratio. Inflammatory biomarkers were exploratory outcomes in the 2DR arm.

\section{Statistical analysis}

$X^{2}$ and Fisher's exact tests were used to assess differences between categorical variables. The student's t-test or Wilcoxon's signed-rank test were used to assess differences between continuous variables. Statistical analyses were performed using SPSS 22.0 (IBM Corporation, Armonk, NY, USA) and GraphPad Prism 6.0 (GraphPad Software, Inc. La Jolla, CA, USA). Values of $\mathrm{P}<0.05$ were considered statistically significant. Multivariate logistic regression analysis was used to identify factors influencing the viral suppression rate at week 12.

\section{Results}

Between September 2, 2019 and January 26, 2020, 73 participants were screened and 69 were enrolled in this study. Genotypic tests were performed by the Chinese Center for Disease Control prior to HAART administration; none of the participants harbored viruses bearing mutations conferring resistance to INSTIs or NRTIs. In the 2DR group, two participants discontinued study follow-up prior to week 36 and were lost to follow-up. In the 3DR group, twelve participants discontinued study follow-up prior to week 8 for the following reasons: moved out of the area $(n=2)$, drug withdrawal $(n=3)$, lost to follow-up $(n=5)$, and change in HAART regimen $(n=2)$ (Fig. 1).

Baseline characteristics were generally similar between the two study arms with the exception that the proportions of participants with opportunistic infections and

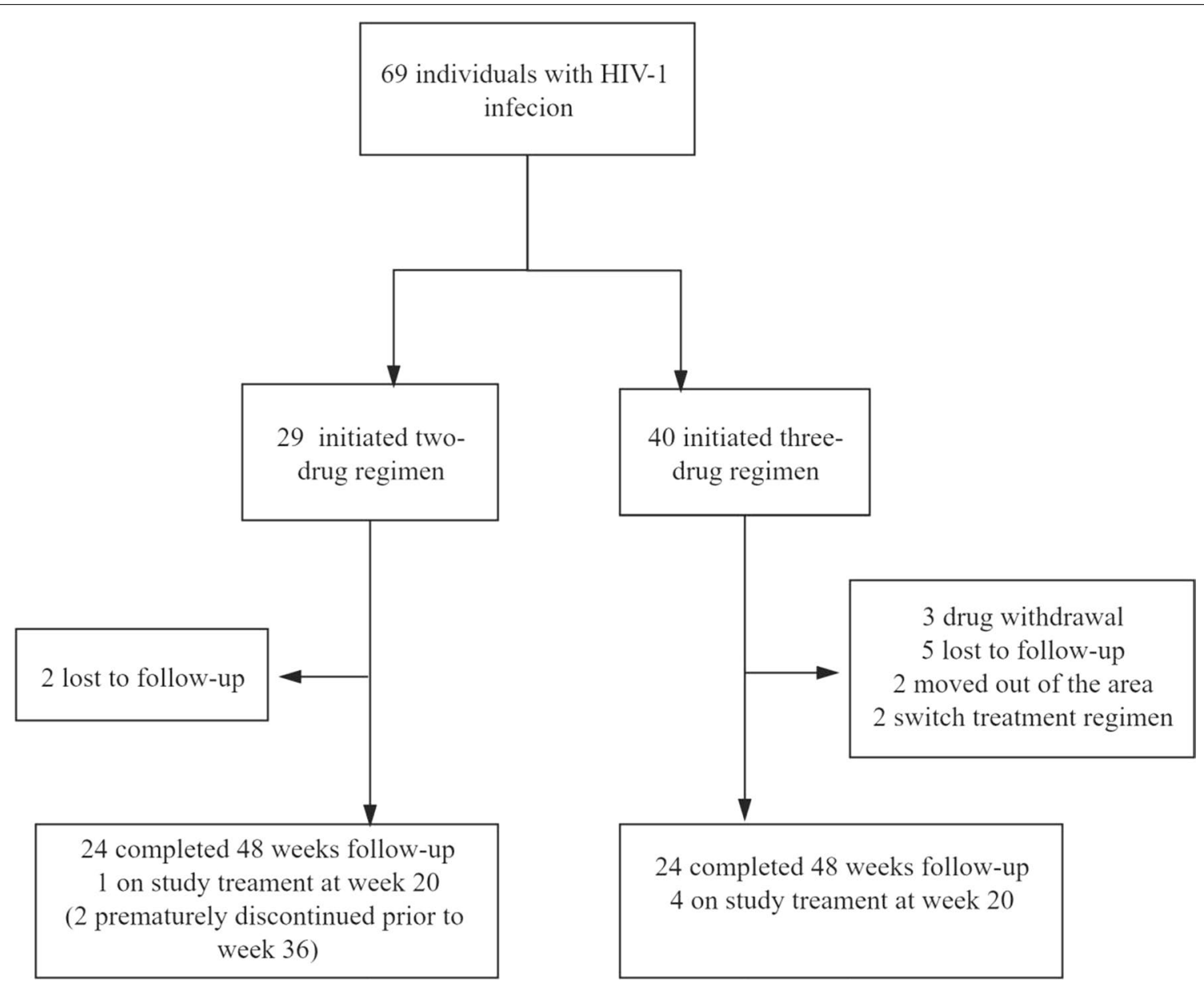

Fig. 1 Study Profile 
Table 1 Baseline demographics and clinical characteristics for the two study arms

\begin{tabular}{|c|c|c|c|}
\hline Characteristic & 2DR & 3DR & $P$ value \\
\hline Age, y, median (range) & $31(24-38)$ & $31(24.25-40)$ & 0.768 \\
\hline Male & $27(100 \%)$ & $23(82.14 \%)$ & 0.051 \\
\hline \multicolumn{4}{|l|}{ Mode of transmission } \\
\hline MSM & $22(81.48 \%)$ & 20 (68.97\%) & 0.38 \\
\hline Heterosexual & $5(18.51 \%)$ & $7(25.00 \%)$ & 0.561 \\
\hline IDU & $0(0 \%)$ & $1(3.57 \%)$ & 1.000 \\
\hline Hepatitis B & $0(0 \%)$ & $3(10.71 \%)$ & 0.236 \\
\hline Hepatitis C & $0(0 \%)$ & $0(0 \%)$ & - \\
\hline $\begin{array}{l}\text { Opportunistic infec- } \\
\text { tions }\end{array}$ & 12 (44.44\%) & $4(14.29 \%)$ & 0.033 \\
\hline Pneumocystosis & $5(18.51 \%)$ & $4(14.29 \%)$ & 0.954 \\
\hline Penicillium Malneffei & $4(14.81 \%)$ & $0(0 \%)$ & 0.051 \\
\hline Cryptococcus & $0(0 \%)$ & $1(3.57 \%)$ & 1.000 \\
\hline Candida & $3(11.11 \%)$ & $1(3.57 \%)$ & 0.352 \\
\hline Tuberculosis & $1(3.7 \%)$ & $0(0 \%)$ & 0.491 \\
\hline Cytomegalovirus & $7(25.93 \%)$ & $2(7.14 \%)$ & 0.129 \\
\hline EB virus & $4(14.81 \%)$ & $1(3.57 \%)$ & 0.305 \\
\hline Bacterial infection & $4(14.81 \%)$ & $3(10.71 \%)$ & 0.916 \\
\hline CD4/CD8 ratio & $0.25 \pm 0.17$ & $0.36 \pm 0.19$ & 0.031 \\
\hline \multicolumn{4}{|l|}{ CD4 + count (cells/ $/ \mathrm{L})$} \\
\hline Mean & $222.07 \pm 176.67$ & $326.55 \pm 194.56$ & 0.044 \\
\hline$\leq 200($ cells $/ \mu \mathrm{L})$ & $13(48.15 \%)$ & $5(17.86 \%)$ & 0.017 \\
\hline 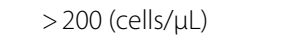 & $14(51.85 \%)$ & $22(78.57 \%)$ & 0.037 \\
\hline \multicolumn{4}{|l|}{ HIV-1 RNA ( copies/mL) } \\
\hline Median (range) & $\begin{array}{l}61,100 \\
(33,500-229,000)\end{array}$ & $\begin{array}{l}42,600 \\
(22,650-91,200)\end{array}$ & 0.167 \\
\hline $\begin{array}{l}\leq 100,000 \text { (copies/ } \\
\mathrm{mL} \text { ) }\end{array}$ & $18(66.67 \%)$ & $24(85.71 \%)$ & 0.179 \\
\hline $\begin{array}{l}>100,000 \text { (copies/ } \\
\text { mL) }\end{array}$ & $9(33.33 \%)$ & $4(14.29 \%)$ & 0.179 \\
\hline ALT & $17.7(12-24)$ & $20.45(14.25-30.3)$ & 0.210 \\
\hline AST & $19(17.5-25.2)$ & $21.40 \pm 5.14$ & 0.705 \\
\hline Creatinine & 75 (67-91) & $77.14 \pm 16.04$ & 0.926 \\
\hline Cystatin & $0.99 \pm 0.38$ & $0.89(0.79-1)$ & 0.076 \\
\hline Urea & $3.94(3.5-4.4)$ & $4.19 \pm 1.15$ & 0.495 \\
\hline $\mathrm{CHOL}$ & $3.79 \pm 1.05$ & $4.09 \pm 1.18$ & 0.328 \\
\hline $\mathrm{HDL}$ & $0.99(0.77-1.15)$ & $1.06 \pm 0.37$ & 0.421 \\
\hline LDL & $2.24 \pm 0.91$ & $2.60 \pm 0.69$ & 0.109 \\
\hline TG & $131 \pm 0.66$ & $1.57(0.7-1.96)$ & 0.441 \\
\hline eGFR & $100.56 \pm 21.18$ & $101.29 \pm 14.23$ & 0.905 \\
\hline
\end{tabular}

Data are presented as mean (SD), medians (interquartile ranges) or No. (\%) IDU, intravenous drug user; MSM, men who have sex with men; ALT, alanine aminotransferase; AST, aspartate aminotransferase; $\mathrm{CHOL}$,total cholesterol; LDL, low-density lipoprotein; HDL, high-density lipoprotein; TG, triglyceride; eGFR, estimated glomerular filtration rate; $2 \mathrm{DR}$, two-drug regimen; 3DR, three-drug regimen

CD4 counts $<200$ cells $/ \mu \mathrm{L}$ were higher in the $2 \mathrm{DR}$ arm compared with the 3DR arm (Table 1). Participants were not included in the endpoint analysis if did not reach the follow-up time window. At week 12, the proportion of participants with HIV RNA $<50$ copies $/ \mathrm{mL}$ in the $2 \mathrm{DR}$ arm was $81.5 \%(22 / 27)$ compared with $53.6 \%(15 / 28)$ in the 3DR arm $(\mathrm{p}<0.01)$ (Table 2). In the 2DR arm, 26 (100\%) participants achieved virologic suppression at week 24 and maintained HIV-1 viral loads $<50$ RNA cop$\mathrm{ies} / \mathrm{mL}$ at week 48 , despite the fact that nine $(33.3 \%)$ participants had baseline HIV-1 RNA viral loads $>100,000$ RNA copies per $\mathrm{mL}$. In the 3DR arm, four (16.7\%) participants did not achieve virologic success at week 24, with HIV-1 RNA levels between 50 and 200 copies/mL; however, all participants achieved virologic suppression at week 48. Virologic rebound had not observed in either study arm between week 24 and week 48. Multivariate logistic regression analysis indicated that none of age, opportunistic infections, CD4 cell counts $<200$ cells/ $\mu \mathrm{L}$, and viral loads $>100,000$ copies/mL were statistically significant determinants of viral suppression at week 12 (Table 3).

Mean baseline CD4 cell counts were 222.07 cells/ $\mu \mathrm{L}$ in the $2 \mathrm{DR}$ arm and 326.55 cells $/ \mu \mathrm{L}$ in the $3 \mathrm{DR}$ arm $(\mathrm{p}=0.044)$. The mean baseline CD4/CD8 ratio was 0.25 in the $2 \mathrm{DR}$ arm and 0.36 in the $3 \mathrm{DR}$ arm $(\mathrm{p}=0.031)$ (Table 1). Mean changes in CD4 counts from baseline to week 12 were 125.46 cells/ $\mu \mathrm{L}$ in the $2 \mathrm{DR}$ arm and 41.20 cells $/ \mu \mathrm{L}$ in the $3 \mathrm{DR}$ arm $(\mathrm{p}=0.026)$. Mean changes in CD4 counts from baseline to week 24 were 209.68 cells/ $\mu \mathrm{L}$ in the $2 \mathrm{DR}$ arm and 73.28 cells $/ \mu \mathrm{L}$ in the 3DR arm $(p=0.020)$ (Table 2). Self-reported adherence was generally high throughout the study period in both arms. Elevated levels of inflammatory biomarkers including IL-6, IL-10, and tumor necrosis factor (TNF)- $\alpha$ were observed in patients with opportunistic infections in the 2DR arm at baseline. A rapid decline and return to normal levels of inflammatory biomarkers was observed by week 4 or week 12 (Fig. 2). Inflammatory biomarkers were not tested in the 3DR arm.

The most frequently reported AEs across both study arms were diarrhea, celialgia, emesis, nausea, fatigue, dizziness, rash, anxiety, and upper respiratory tract infection (Table 4). Numerically, fewer participants reported drug-related AEs in the 2DR arm than in the 3DR arm. There was a higher proportion of participants with dizziness in the 3DR arm $(n=15)$ than in the 2DR arm $(n=2)$ $(p=0.009)$. Drug-related AEs leading to drug withdrawal or a change in treatment regimen occurred in five participants in the 3DR arm (grade 4 hepatic damage, $n=2$; grade $3 / 4$ rash, $n=3$ ) and in no participants in the $2 D R$ arm.

Elevated levels of alanine aminotransferase were more common in the 3DR arm than in the 2DR arm $(\mathrm{p}=0.006)$ (Table 2$)$. Increases in creatinine from baseline were observed in $11.11 \%(3 / 27)$ of participants in 
Table 2 Snapshot analysis of participants after ART treatment

\begin{tabular}{|c|c|c|c|}
\hline Characteristic & 2DR & 3DR & $P$ value \\
\hline \multicolumn{4}{|l|}{ HIV-1 RNA ( $<50$ copies/mL) } \\
\hline Week 12 & $25(92.5 \%)$ & $15(53.57 \%)$ & 0.003 \\
\hline Week 24 & $26(100 \%)$ & $20(83.3 \%)$ & 0.046 \\
\hline Week48 & $24(100 \%)$ & $24(100 \%)$ & 1.000 \\
\hline \multicolumn{4}{|c|}{ Change From Baseline in CD4 + count (cells $/ \mu \mathrm{L}$ ) } \\
\hline Week 12 & $125.46 \pm 149.38$ & $41.2 \pm 110.60$ & 0.026 \\
\hline Week 24 & $209.68 \pm 175.88$ & $73.28 \pm 162.40$ & 0.020 \\
\hline Week48 & $204.73 \pm 287.32$ & $163.21 \pm 121.15$ & 0.805 \\
\hline \multicolumn{4}{|c|}{ Change From Baseline in CD4/CD8 ratio } \\
\hline Week 12 & $0.11(0.02-0.31)$ & $0.21(0.11-0.35)$ & 0.058 \\
\hline Week 24 & $0.15(0.09-0.36)$ & $0.26(0.12-0.49)$ & 0.170 \\
\hline Week48 & $0.13(0.07-0.39)$ & $0.23(0.10-0.61)$ & 0.492 \\
\hline \multicolumn{4}{|c|}{ Change From Baseline to week 48 in Laboratory Results } \\
\hline ALT & $-3.2(-4.55-1.1)$ & $5(-0.85-16.35)$ & 0.004 \\
\hline AST & $-4.38 \pm 7.64$ & $1.11 \pm 10.41$ & 0.217 \\
\hline Cystatin & $-0.1 \pm 0.122$ & $-0.07 \pm 0.10$ & 0.439 \\
\hline Urea & $-0.01 \pm 1.31$ & $-0.19 \pm 1.13$ & 0.716 \\
\hline eGFR & $-17.27 \pm 24.87$ & $2.84(-7.1-22.08)$ & 0.052 \\
\hline Hypercholesterolemia & $1(3.70 \%)$ & $2(7.14 \%)$ & 1 \\
\hline Hypertriglyceridemia & $3(11.11 \%)$ & $5(17.86 \%)$ & 0.744 \\
\hline Elevated LDL & $1(3.70 \%)$ & $0(0 \%)$ & 0.49 \\
\hline Elevated HDL & $2(7.41 \%)$ & $8(28.57 \%)$ & 0.092 \\
\hline Elevated creatinine & $3(11.11 \%)$ & $1(3.57 \%)$ & 0.577 \\
\hline
\end{tabular}

Data are presented as mean (SD), medians (interquartile ranges) or No. (\%)

Abbreviations: ALT, alanine aminotransferase; AST, aspartate aminotransferase; LDL, low-density lipoprotein; HDL, high-density lipoprotein; eGFR, estimated glomerular filtration rat; 2DR, two-drug regimen; 3DR, three-drug regimen

Table 3 Results of multivariate regression analysis

\begin{tabular}{|c|c|c|}
\hline Variable & OR ( $95 \% \mathrm{Cl})$ & $P$ value \\
\hline \multicolumn{3}{|l|}{ Age } \\
\hline $2 \mathrm{DR}$ & $0.65(0.25,0.88)$ & 0.11 \\
\hline $3 \mathrm{DR}$ & $1.03(0.94,1.14)$ & 0.6 \\
\hline \multicolumn{3}{|c|}{ Combined with Ols } \\
\hline $2 \mathrm{DR}$ & 1629 (NA, 1.10) & 0.2 \\
\hline $3 D R$ & $0.22(0.00,4.20)$ & 0.3 \\
\hline \multicolumn{3}{|c|}{ CD4 cell counts $<200$ cells $/ \mu \mathrm{L}$} \\
\hline $2 \mathrm{DR}$ & $0.00(0.00,0.07)$ & 0.9 \\
\hline $3 D R$ & $1.01(0.07,24.7)$ & 1.0 \\
\hline \multicolumn{3}{|c|}{ VL $>100,000$ copies $/ m L$} \\
\hline $2 \mathrm{DR}$ & $0.01(0.00,16.6)$ & 0.3 \\
\hline $3 D R$ & 0.00 & 1.0 \\
\hline
\end{tabular}

2DR, two-drug regimen; 3DR, three-drug regimen; Ols, opportunistic infections; VL, viral load

the 2DR arm and 3.5\% (1/28) of participants in the 3DR $\operatorname{arm}(\mathrm{p}=0.577)$. No significant differences were observed between the 2DR and 3DR arms in mean changes from baseline in cystatin, urea, or estimated glomerular filtration rate (eGFR) at week 48. Elevated cholesterol, triglycerides, low density lipoprotein (LDL) were observed in both study arms. The proportions of participants with hypercholesterolemia, hypertriglyceridemia, and increased LDL were similar in both study arms.

\section{Discussion}

In this ongoing prospective cohort study, we analyzed the efficacy and safety of DTG +3 TC compared with EFV + TDF + 3TC among ART-naive adults in China. DTG +3TC was non-inferior to the standard 3DR $(\mathrm{EFV}+\mathrm{TDF}+3 \mathrm{TC})$ through 48 weeks of treatment. Multivariate logistic regression analysis indicated that none of age, opportunistic infections, CD4 cell counts, and HIV-1 viral loads $>100,000$ copies/mL were independently associated with treatment outcome. Importantly, the more rapid reduction in viral load at week 12 in the 2DR demonstrated that DTG + 3TC was statistically superior to the 3DR. In addition, increases in CD4 cell counts from baseline to week 12 and week 24 were more rapid in the 2DR arm than in the 3DR arm. The rapid reduction in viral load may be responsible for the immune reconstitution observed in the 2DR arm. 


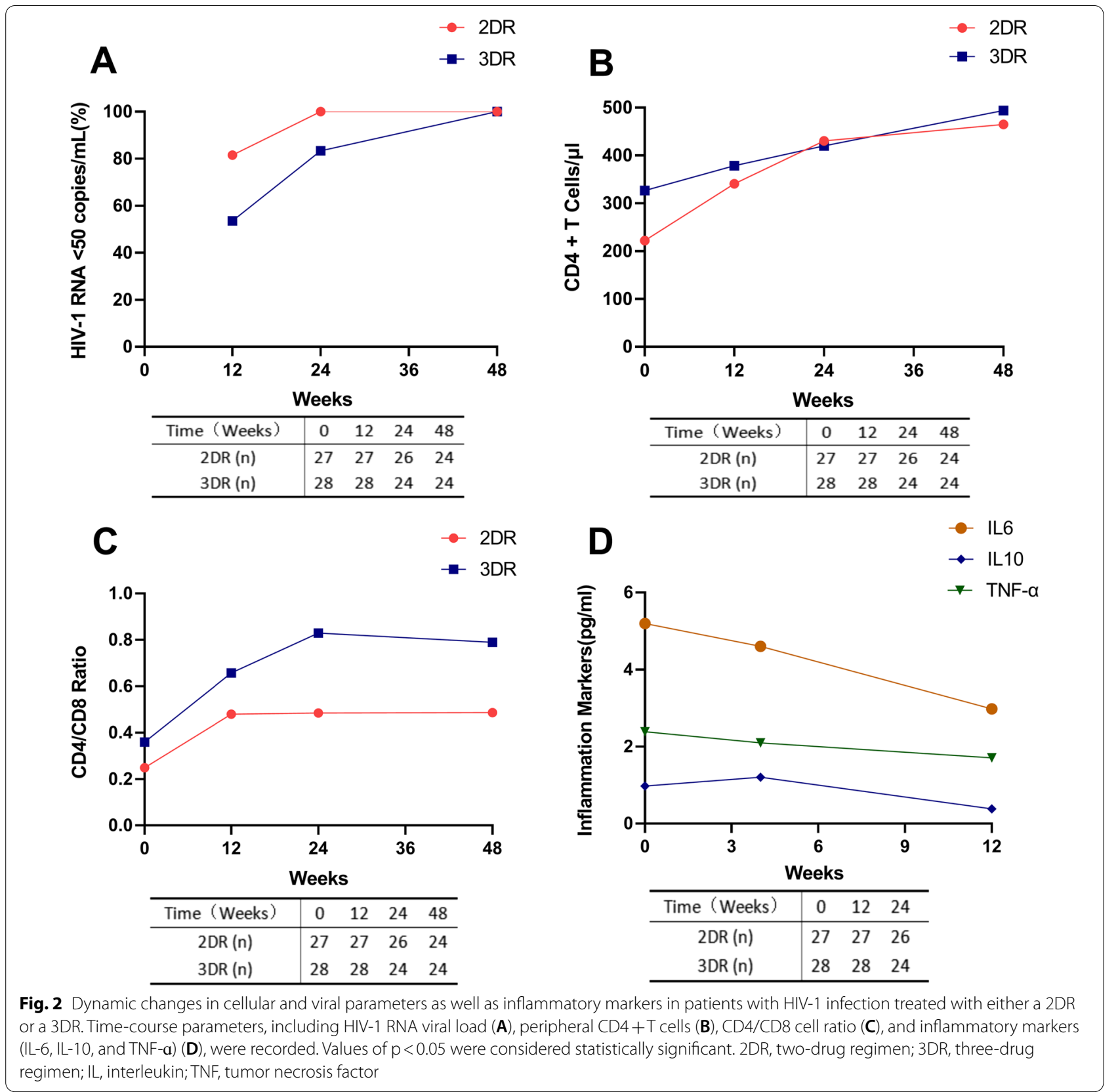

Data from the SINGLE study demonstrated the superior efficacy and better tolerability of DTG + abacavir + 3TC compared with EFV + TDF + FTC [20]. The GEMINI studies showed non-inferior virological efficacy of a 2DR (DTG + 3TC) compared with a recommended 3DR (DTG+TDF/FTC) in the first adequately powered, randomized, controlled studies of DTG + 3TC in HAART-naive patients with baseline viral loads of less than 500,000 copies/mL $[12,13]$. Our study confirms key virological findings of the ACTG A5353 and PADDLE studies $[6,21]$. In previous studies, 2DRs have been used as in treatment-experienced individuals with virologic suppression and showed safety and efficacy in maintaining viral suppression [38-41]. In recent years, data from real world studies have documented the feasibility and efficacy of 2DRs in ART-naive individuals [42-44].

Strikingly, both mean CD4 cell counts and CD4/CD8 ratios were lower in the $2 \mathrm{DR}$ arm compared with the 3DR arm at baseline. Low CD4 cell counts are strongly correlated with high HIV-1 RNA levels [22-24]. Low CD4/CD8 ratios are associated with increased risks of 
Table 4 Adverse events overview

\begin{tabular}{llll}
\hline Adverse events & 2DR & 3DR & P value \\
\hline Agrypnia $^{\mathrm{a}}$ & $0(0 \%)$ & $3(10.71 \%)$ & 0.236 \\
Anxiety/depression $^{\mathrm{a}}$ & $1(3.70 \%)$ & $1(3.5 \%)$ & 1 \\
Loss of appetite $^{\mathrm{a}}$ & $1(3.70 \%)$ & $3(10.71 \%)$ & 0.63 \\
Diarrhea/celialgia $^{\mathrm{a}}$ & $1(3.70 \%)$ & $2(7.14 \%)$ & 0.97 \\
Nausea $^{\mathrm{a}}$ & $1(3.70 \%)$ & $2(7.14 \%)$ & 0.97 \\
Vomiting $^{\text {a }}$ & $0(0 \%)$ & $5(17.86 \%)$ & 0.051 \\
Fatigue $^{\mathrm{a}}$ & $4(14.81 \%)$ & $3(10.71 \%)$ & 1 \\
Dizzy $^{\mathrm{a}}$ & $2(7.41 \%)$ & $15(53.57 \%)$ & 0.009 \\
Upper respiratory tract infection $^{\mathrm{a}}$ & $4(14.81 \%)$ & $3(10.71 \%)$ & 1 \\
Rash $^{\mathrm{a}}$ & $6(22.22 \%)$ & $9(28.57 \%)$ & 0.589 \\
SAEs & $0(0 \%)$ & $5(15.15 \%)$ & 0.058 \\
\hline
\end{tabular}

SAE, serious adverse event; 2DR, two-drug regimen; 3DR, three-drug regimen

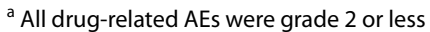

morbidity and mortality, and are prognostic of nonAIDS defining events in HIV-1-infected individuals [25-27]. The proportion of patients with opportunistic infections was higher in the 2DR arm compared with the 3DR arm. Numerically, the proportion of participants with viral loads above 100,000 RNA copies/mL was higher in the 2DR arm compared with the 3DR arm. Thus, the proportion of patients with advanced HIV-1 infection was higher in the 2DR arm.

There are continuing challenges in managing HIV-1 infection, particularly in older patients who often experience age-related comorbidities resulting in complex polypharmacy and increased risks of DDIs [28]. DTG has minimal drug interactions because its major and minor metabolic pathways are uridine $5^{\prime}$-diphosphoglucuronosyltransferase $1 \mathrm{~A} 1$ and cytochrome 3A4, respectively [29]. In this study, the rate of virological suppression reached $92.5 \%$ at week 12 and $100 \%$ at week 24 in the 2DR arm. Taken together, the findings of this study demonstrated the superiority of a 2DR containing DTG in patients with advanced HIV-1 infection compared with the standard 3DR.

Increases in CD4 cell counts from baseline to week 12 and week 24 occurred more rapidly in the 2DR arm than in the 3DR arm. The recovery of CD4 cell counts reflects immune reconstitution. INSTIs, especially DTG and EVG, are associated with a higher probability of development of immune reconstitution inflammatory syndrome (IRIS) [30]. Inflammation is associated with untreated HIV-1 infection, and high baseline levels of IL-6, IL-10, and TNF- $\alpha$ are associated with increased risks of AIDS-defining events [31, 32]. In this study, elevated levels of inflammatory biomarkers including IL-6, IL-10, and TNF- $\alpha$ in the 2DR arm declined rapidly and returned to normal levels by week
4 or week 12 . There were no signs of IRIS in patients with advanced HIV-1 in the 2DR arm.

Higher frequencies of drug-related AEs were observed in the 3DR arm than in the 2DR arm in this study, especially grade 1 or grade 2 dizziness. This finding was consistent with the toxicity profile of EFV, which includes neuropsychiatric AEs such as abnormal dreams, sleep disturbances, anxiety, depression, and dizziness [33, 34]. DTG + 3TC was well tolerated through 48 weeks with no additional or unexpected SAEs.

Drug induced liver injury (DILI) is a common and challenging $\mathrm{AE}$ in patients receiving EFV-based HAART regimens [35]. A total of $28.6 \%$ of participants with DILI had hepatocellular or mixed hepatocellular lesions (grade 1 or 2). Two patients withdrew from treatment because of grade 4 cholestasis liver injury. It had been reported that DTG results in increased levels of serum.

creatinine and moderate reductions in eGFR without changes in the iohexol-measured glomerular filtration rate [36]. In this study, changes in creatinine level at week 48 relative to baseline were more frequent in the 2DR arm. Given the higher rate of opportunistic infections in the 2DR arm, it seems possible that antifungal agents, especially amphotericin $\mathrm{B}$ because of its renal toxicity [37], were responsible for elevated creatinine levels. No significant differences between the 2DR and 3DR arms were observed in mean change from baseline in cystatin, urea, or eGFR at week 48 .

There were several limitations to our study. This was an observational study with a limited sample size, which could lead to bias. In addition, the study enrolled predominantly men with a median age of 31 years. Because of the limited study duration, a roll-over study with 96-week and 144-week follow-up is ongoing to show the durable efficacy and safety of DTG + 3TC.

\section{Conclusions}

Administration of DTG + 3TC achieved virologic suppression rapidly and with good immune reconstitution at weeks 12 and 24 in HAART-naive individuals, regardless of baseline viral load and with no CD4 cell count restrictions. DTG +3TC could represent an optimal regimen for ART-naïve patients with advanced HIV-1 infection, especially those who require complex treatment plans or wish to minimize potential drug toxicity or DDIs.

\section{Acknowledgements}

We acknowledge all health-care workers involved in the diagnosis and treatment of patients in the Fifth Affiliated Hospital, Sun Yat-sen University and thank all patients and their families involved in the study.

\section{Authors' contributions}

$Z \mathrm{Z}, J X, L D$, and $C L$ performed the study. $L D, C L$, and $P C$ analyzed the data and wrote the manuscript. XL, XZ, LZ, YZ provided clinical data. ZH helped edit the paper. JX, ZH supervised the study and applied for grants. All authors read and approved the final manuscript. 


\section{Funding}

Zhuhai science and technology projects (ZH2202200017HJL) and Key Laboratory of tropical disease prevention and control, Yat-sen sen University (2018kfkt). The importation mechanism and spreading rules of imported infectious diseases (2016YFC1200105).

\section{Availability of data and materials}

The datasets used or analysed during the current study available from the corresponding author on reasonable request.

\section{Declarations}

\section{Ethics approval and consent to participate}

The study was approved by The Research Ethics Committee at The Fifth Affiliated Hospital of Sun Yat-Sen University (No.ZDWY[2019] Lunzi No.K16-1). Written informed consent was obtained from each participant before the initiation of study procedures. All methods were performed in accordance with the relevant guidelines and regulations.

\section{Consent for publication}

Not applicable.

\section{Competing interests}

The authors declare no conflict of interest.

\section{Author details}

'Department of Infectious Diseases, the Fifth Affiliated Hospital, Sun Yat-Sen University, 52 East Meihua Road, Zhuhai 519000, Guangdong, China. ${ }^{2}$ Center for Disease Control and Prevention, Zhuhai 519000, China.

\section{Received: 30 September 2021 Accepted: 17 December 2021}

Published online: 04 January 2022

\section{References}

1. Samji H, Cescon A, Hogg RS, Modur SP, Althoff KN, Buchacz K, Burchell AN, Cohen M, Gebo KA, Gill MJ, et al. Closing the gap: increases in life expectancy among treated HIV-positive individuals in the United States and Canada. PLoS ONE. 2013;8(12):e81355.

2. Mocroft A, Ledergerber B, Katlama C, Kirk O, Reiss P, D'Arminio MA, Knysz B, Dietrich M, Phillips AN, Lundgren JD. Decline in the AIDS and death rates in the EuroSIDA study: an observational study. Lancet. 2003:362(9377):22-9.

3. Peter J, Choshi P, Lehloenya RJ. Drug hypersensitivity in HIV infection. Curr Opin Allergy Clin Immunol. 2019;19(4):272-82.

4. Marzolini C, Elzi L, Gibbons S, Weber R, Fux C, Furrer H, Chave JP, Cavassini M, Bernasconi E, Calmy A, et al. Prevalence of comedications and effect of potential drug-drug interactions in the Swiss HIV Cohort Study. Antivir Ther. 2010;15(3):413-23.

5. Pulido F, Ribera E, Lagarde M, Perez-Valero I, Palacios R, Iribarren JA, Payeras A, Domingo P, Sanz J, Cervero M, et al. Dual therapy with darunavir and ritonavir plus lamivudine vs triple therapy with darunavir and ritonavir plus tenofovir disoproxil fumarate and emtricitabine or abacavir and lamivudine for maintenance of human immunodeficiency virus type 1 viral suppression: randomized, open-label, Noninferiority DUAL-GESIDA 8014-RIS-EST45 trial. Clin Infect Dis. 2017:65(12):2112-8.

6. van Wyk J, Ajana F, Bisshop F, De Wit S, Osiyemi O, Portilla SJ, Routy JP, Wyen C, Ait-Khaled M, Nascimento MC, et al. Efficacy and safety of switching to dolutegravir/lamivudine fixed-dose 2-drug regimen vs continuing a tenofovir alafenamide-based 3- or 4-drug regimen for maintenance of virologic suppression in adults living with human immunodeficiency virus type 1: phase 3, randomized, noninferiority TANGO study. Clin Infect Dis. 2020;71(8):1920-9.

7. Llibre JM, Hung CC, Brinson C, Castelli F, Girard PM, Kahl LP, Blair EA, Angelis K, Wynne B, Vandermeulen K, et al. Efficacy, safety, and tolerability of dolutegravir-rilpivirine for the maintenance of virological suppression in adults with HIV-1: phase 3, randomised, non-inferiority SWORD-1 and SWORD-2 studies. Lancet. 2018;391(10123):839-49.
8. Min S, Sloan L, DeJesus E, Hawkins T, McCurdy L, Song I, Stroder R, Chen S, Underwood M, Fujiwara T, et al. Antiviral activity, safety, and pharmacokinetics/pharmacodynamics of dolutegravir as 10-day monotherapy in HIV-1-infected adults. AIDS. 2011;25(14):1737-45.

9. Brenner BG, Wainberg MA. Clinical benefit of dolutegravir in HIV-1 management related to the high genetic barrier to drug resistance. Virus Res. 2017;239:1-9.

10. Kelly SG, Nyaku AN, Taiwo BO. Two-drug treatment approaches in HIV: finally getting somewhere? Drugs. 2016;76(5):523-31.

11. Cahn P, Andrade-Villanueva J, Arribas JR, Gatell JM, Lama JR, Norton M, Patterson P, Sierra MJ, Sued O, Figueroa MI, et al. Dual therapy with lopinavir and ritonavir plus lamivudine versus triple therapy with lopinavir and ritonavir plus two nucleoside reverse transcriptase inhibitors in antiretroviral-therapy-naive adults with HIV-1 infection: 48 week results of the randomised, open label, non-inferiority GARDEL trial. Lancet Infect Dis. 2014;14(7):572-80.

12. Cahn P, Madero JS, Arribas JR, Antinori A, Ortiz R, Clarke AE, Hung CC, Rockstroh JK, Girard PM, Sievers J, et al. Dolutegravir plus lamivudine versus dolutegravir plus tenofovir disoproxil fumarate and emtricitabine in antiretroviral-naive adults with HIV-1 infection (GEMINI-1 and GEMINI-2): week 48 results from two multicentre, double-blind, randomised, noninferiority, phase 3 trials. Lancet. 2019;393(10167):143-55.

13. Cahn P, Madero JS, Arribas JR, Antinori A, Ortiz R, Clarke AE, Hung CC, Rockstroh JK, Girard PM, Sievers J, et al. Durable efficacy of dolutegravir plus lamivudine in antiretroviral treatment-naive adults with HIV-1 infection: 96-week results from the GEMINI-1 and GEMINI-2 randomized clinical trials. J Acquir Immune Defic Syndr. 2020;83(3):310-8.

14. Rathbun RC, Lockhart SM, Miller MM, Liedtke MD. Dolutegravir, a secondgeneration integrase inhibitor for the treatment of HIV-1 infection. Ann Pharmacother. 2014;48(3):395-403.

15. Brenchley JM, Price DA, Schacker TW, Asher TE, Silvestri G, Rao S, Kazzaz Z, Bornstein E, Lambotte O, Altmann D, et al. Microbial translocation is a cause of systemic immune activation in chronic HIV infection. Nat Med. 2006;12(12):1365-71.

16. Martinez-Picado J, Deeks SG. Persistent HIV-1 replication during antiretroviral therapy. Curr Opin HIV AIDS. 2016;11(4):417-23.

17. Deeks SG, Tracy R, Douek DC. Systemic effects of inflammation on health during chronic HIV infection. Immunity. 2013;39(4):633-45.

18. Hunt PW, Sinclair E, Rodriguez B, Shive C, Clagett B, et al. Gut epithelial barrier dysfunction and innate immune activation predict mortality in treated HIV infection. J Infect Dis. 2014;210(8):1228-38.

19. National Institute of Allergy and Infectious Diseases, National Institutes of Health, US Department of Health and Human Services. Division of AIDS (DAIDS) Table for Grading the Severity of Adult and Pediatric Adverse Events, v.2.0. https://rsc.niaid.nih.gov/clinical-research-sites/table-gradi ng-severity-adult-pediatric-adverse-events-version-two. Accessed 3 July.

20. Walmsley S, Baumgarten A, Berenguer J, Felizarta F, Florence E, KhuongJosses MA, Kilby JM, Lutz T, Podzamczer D, Portilla J, et al. Brief report: Dolutegravir Plus Abacavir/lamivudine for the treatment of HIV-1 Infection in antiretroviral therapy-naive patients: week 96 and week 144 results from the SINGLE randomized clinical trial. J Acquir Immune Defic Syndr. 2015;70(5):515-9.

21. Cahn P, Rolon MJ, Figueroa MI, Gun A, Patterson P, Sued O. Dolutegravirlamivudine as initial therapy in HIV-1 infected, ARV-naive patients, 48-week results of the PADDLE (Pilot Antiretroviral Design with Dolutegravir LamivudinE) study. J Int AIDS Soc. 2017;20(1):21678.

22. Boulassel MR, Chomont N, Pai NP, Gilmore N, Sekaly RP, Routy JP. CD4 T cell nadir independently predicts the magnitude of the HIV reservoir after prolonged suppressive antiretroviral therapy. J Clin Virol. 2012;53(1):29-32

23. Watanabe D, Ibe $S$, Uehira T, Minami R, Sasakawa A, Yajima K, Yonemoto $H$ Bando H, Ogawa Y, Taniguchi T, et al. Cellular HIV-1 DNA levels in patients receiving antiretroviral therapy strongly correlate with therapy initiation timing but not with therapy duration. BMC Infect Dis. 2011;11:146.

24. Burgard M, Boufassa F, Viard JP, Garrigue I, Ruffault A, Izopet J, Vabret A, Descamps D, Colson P, Seigneurin JM, et al. Factors influencing peripheral blood mononuclear cell-associated HIV-1 DNA level after long-term suppressive antiretroviral therapy in 236 patients. AIDS. 2009;23(16):2165-71.

25. Han WM, Apornpong T, Kerr SJ, Hiransuthikul A, Gatechompol S, Do T, Ruxrungtham K, Avihingsanon A. CD4/CD8 ratio normalization rates and low ratio as prognostic marker for non-AIDS defining events among 
long-term virologically suppressed people living with HIV. AIDS Res Ther. 2018;15(1):13.

26. Trickey A, May MT, Schommers P, Tate J, Ingle SM, Guest JL, Gill MJ, Zangerle R, Saag M, Reiss P, et al. CD4:CD8 ratio and CD8 count as prognostic markers for mortality in human immunodeficiency virus-infected patients on antiretroviral therapy: the antiretroviral therapy cohort collaboration (ART-CC). Clin Infect Dis. 2017;65(6):959-66.

27. Serrano-Villar S, Sainz T, Lee SA, Hunt PW, Sinclair E, Shacklett BL, Ferre AL, Hayes TL, Somsouk M, Hsue PY, et al. HIV-infected individuals with low CD4/CD8 ratio despite effective antiretroviral therapy exhibit altered $T$ cell subsets, heightened CD8+ T cell activation, and increased risk of non-AIDS morbidity and mortality. PLoS Pathog. 2014;10(5):e1004078.

28. Back D, Marzolini C. The challenge of HIV treatment in an era of polypharmacy. J Int AIDS Soc. 2020;23(2):e25449.

29. Cottrell ML, Hadzic T, Kashuba AD. Clinical pharmacokinetic, pharmacodynamic and drug-interaction profile of the integrase inhibitor dolutegravir. Clin Pharmacokinet. 2013;52(11):981-94.

30. Psichogiou M, Basoulis D, Tsikala-Vafea M, Vlachos S, Kapelios CJ, Daikos GL. Integrase strand transfer inhibitors and the emergence of immune reconstitution inflammatory syndrome (IRIS). Curr HIV Res. 2017;15(6):405-10.

31. McComsey GA, Kitch D, Sax PE, Tierney C, Jahed NC, Melbourne K, Ha B, Brown TT, Bloom A, Fedarko N, et al. Associations of inflammatory markers with AIDS and non-AIDS clinical events after initiation of antiretroviral therapy: AIDS clinical trials group A5224s, a substudy of ACTG A5202. J Acquir Immune Defic Syndr. 2014;65(2):167-74.

32. de Medeiros RM, Valverde-Villegas JM, Junqueira DM, GrafT, Lindenau JD, de Mello MG, Vianna P, Almeida SE, Chies JA. Rapid and Slow Progressors Show Increased IL-6 and IL-10 Levels in the Pre-AIDS Stage of HIV Infection. PLoS ONE. 2016;11(5):e156163.

33. Tozzi V, Balestra P, Salvatori MF, Vlassi C, Liuzzi G, Giancola ML, Giulianelli $M$, Narciso P, Antinori A. Changes in cognition during antiretroviral therapy: comparison of 2 different ranking systems to measure antiretroviral drug efficacy on HIV-associated neurocognitive disorders. J Acquir Immune Defic Syndr. 2009;52(1):56-63.

34. Wise ME, Mistry K, Reid S. Drug points: Neuropsychiatric complications of nevirapine treatment. BMJ. 2002;324(7342):879.

35. Yimer G, Gry M, Amogne W, Makonnen E, Habtewold A, Petros Z, Aderaye G, Schuppe-Koistinen I, Lindquist L, Aklillu E. Evaluation of patterns of liver toxicity in patients on antiretroviral and anti-tuberculosis drugs: a prospective four arm observational study in ethiopian patients. PLOS ONE. 2014;9(4):e94271.

36. Chan JF, Yuan S, Kok KH, To KK, Chu H, Yang J, Xing F, Liu J, Yip CC, Poon RW, et al. A familial cluster of pneumonia associated with the 2019 novel coronavirus indicating person-to-person transmission: a study of a family cluster. Lancet. 2020;395(10223):514-23.

37. Tiphine M, Letscher-Bru V, Herbrecht R. Amphotericin B and its new formulations: pharmacologic characteristics, clinical efficacy, and tolerability. Transpl Infect Dis. 1999;1(4):273-83.

38. Ciccullo A, Baldin G, Capetti A, Rusconi S, Sterrantino G, D'Ettorre G, Colafigli M, Modica S, Lagi F, Giacomelli A, et al. A comparison between two dolutegravir-based two-drug regimens as switch strategies in a multicentre cohort of HIV-1-infected patients. Antivir Ther. 2019;24(1):63-7.

39. Borghetti A, Baldin G, Lombardi F, Ciccullo A, Capetti A, Rusconi S, Sterrantino G, Latini A, Cossu MV, Gagliardini R et al: Efficacy and tolerability of lamivudine plus dolutegravir as a switch strategy in a multicentre cohort of patients with suppressed HIV-1 replication. HIV Med 2018.

40. Borghetti A, Lombardi F, Gagliardini R, Baldin G, Ciccullo A, Moschese D, Emiliozzi A, Belmonti S, Lamonica S, Montagnani F, et al. Efficacy and tolerability of lamivudine plus dolutegravir compared with lamivudine plus boosted PIs in HIV-1 positive individuals with virologic suppression: a retrospective study from the clinical practice. BMC Infect Dis. 2019;19(1):59.

41. Baldin G, Ciccullo A, Rusconi S, Capetti A, Sterrantino G, Colafigli M, D'Ettorre G, Giacometti A, Cossu MV, Borghetti A, et al. Long-term data on the efficacy and tolerability of lamivudine plus dolutegravir as a switch strategy in a multi-centre cohort of HIV-1-infected, virologically suppressed patients. Int J Antimicrob Agents. 2019;54(6):728-34.

42. Ciccullo A, Baldin G, Cossu MV, Passerini M, Borghetti A, Capetti A, Di Giambenedetto S. Dolutegravir Plus Lamivudine as First-Line Regimen in a Multicenter Cohort of HIV-1-infected patients: preliminary data from clinical practice. AIDS Res Hum Retroviruses. 2020;36(1):4-5.
43. Mendoza I, Lazaro A, Torralba M. Effectiveness, Durability, and Safety of Dolutegravir and Lamivudine Versus Dolutegravir, Lamivudine, and Abacavir in a real-life cohort of HIV-infected adults. Ann Pharmacother. 2021;1:276795456.

44. Rolle CP, Berhe M, Singh T, Ortiz R, Wurapa A, Ramgopal M, Leone PA, Matthews JE, Dalessandro M, Underwood MR, et al. Dolutegravir/lamivudine as a first-line regimen in a test-and-treat setting for newly diagnosed people living with HIV. AIDS. 2021;35(12):1957-65.

\section{Publisher's Note}

Springer Nature remains neutral with regard to jurisdictional claims in published maps and institutional affiliations.
Ready to submit your research? Choose BMC and benefit from:

- fast, convenient online submission

- thorough peer review by experienced researchers in your field

- rapid publication on acceptance

- support for research data, including large and complex data types

- gold Open Access which fosters wider collaboration and increased citations

- maximum visibility for your research: over $100 \mathrm{M}$ website views per year

At BMC, research is always in progress.

Learn more biomedcentral.com/submissions 